\title{
Measurement Motoric System of Cerebral Palsy Disability using Gross Motor Function Measure (GMFM)
}

\author{
Aris Rakhmadi*, Ragil Ariyanto \\ Informatics Department \\ Universitas Muhammadiyah Surakarta \\ Surakarta, Indonesia \\ *aris.rakhmadi@ums.ac.id
}

\begin{abstract}
Cerebral palsy (CP) is a mobility disorder, muscle tone or posture disruption caused by brain damage that appears during brain growth, and often occurs before birth. CP has an impact on the daily activities of the suffered patient. Gross Motor Function Measure (GMFM) is a type of clinical measurement to evaluate development progress in the motoric function of CP patients. The purpose of this research is to design software to monitor and evaluate motoric parameters of CP patients. The software implements the GMFM method. The development mechanism went through the process of Software Requirements Specification (SRS). The result shows that the software helps monitor and evaluate CP patients. Software application in the field assists in evaluating the initial examination of T-1 until the final examination of T-6. Records show the enhancement dimensions of lying and rolling by $13.3 \%$, sitting $14.8 \%$, crawling and kneeling by $15.7 \%$, standing by $16.5 \%$, and walking-running-jumping $17.4 \%$. We conclude that the application supports recording and analyzing motoric cerebral palsy data.
\end{abstract}

Keywords: Cerebral palsy, child, Gross Motor Function Measure (GMFM), Unified Software Development Process

Article info: submitted August 14, 2020, revised October 21, 2020, accepted March 29, 2021

\section{Introduction}

World Health Organization (WHO) in 2003 estimated that the number of disabilities in Indonesia around $7-10 \%$ of the total population of Indonesia. Most of the children with disabilities or around 292,250 children are in the community under the guidance and supervision of parents and families. In general, they have not received proper health services[1]. This disability arises because of congenital birth or acquired after birth. The factors that influence are natal, prenatal, postnatal, and socioeconomic[2].

Cerebral palsy (CP) describes a group of permanent disorders of the development of movement and posture, causing activity limitation [3]. Cerebral palsy (CP) is a disorder of movement, muscle tone, or posture caused by brain damage that occurs during the period of brain development, and most often occurs before birth. CP is a form of the physical disability that is most often found in childhood. Although CP is non-progressive, it has an impact on the daily life activities of people with $\mathrm{CP}$ for their whole life. The most obvious characteristic of $\mathrm{CP}$ is motoric disorders including spasticity, motoric control disorders, and muscle weakness. This motoric disturbance can cause limitations in mobility activities related to walking or climbing stairs. In recent decades, the prevalence of CP throughout the world continues to increase, including the prevalence in Indonesia[4].

Most of the relatives around the CP patient do not have latrines and still keep pets around the backyard, therefore the surroundings become increasingly slum-like. In the Puskesmas, during Posyandu services, programs are made to assists counseling to the community of pregnant women to check their pregnancies, therefore that initial abnormalities in pregnancy can be identified and they can be treated promptly and adequately. Furthermore, mothers of under-five children are also given counseling on how to identify signs of child malnutrition and how to provide correct food for toddlers, as a result, the problem of malnutrition and malnutrition can be decreased in the area of the Puskesmas[5].

Research [6] stated that although discussion about the characterization of $\mathrm{CP}$ has tracked a trajectory, the discussion about the initial age at which CP can be precisely diagnosed is a recurrent theme. The idea that premature diagnosis is vital to guarantee early access to illness-specific intervention to reduce the influence of $\mathrm{CP}$ has been elevated in the literature for centuries. As far back as the 
first explanation of cases of CP in the 1800s, William Little made the argument for earliest potential identification with the purpose of "stimulate favorable treatment of the disorders when identified in the early phases". This started the generally recurring argument that earlier diagnosis can lead to the earliest potential intervention.

Kids with CP usually present with growing delay and motor deficits. The variance between a static (non-progressive) and progressive medical course is very significant. Naturally, loss of previously acquired milestones (regression) marks the onset of most metabolic and neurodegenerative disorders (NDD). However, some NDD or metabolic disorders take a slow rate of advancement and can be misdiagnosed as CP. Consequently, perfect developmental regression may not be evident, particularly in the early phases of the illness or at a younger age of onset. Furthermore, the neurological consequences of CP may be postponed for several months because of the immaturity of the nervous system[7].

Research [8] provides a checklist approach that defines the roles of various healthcare providers. The checklist is an instrument that respects the time-based priority of data collection using different numbers: 1,2 , and 3. It contains five vertical pillars in which the third and the fourth are the most significant ones for the checklist: a notice to accumulate all the important data that can be valuable in the upcoming assessment of the case.

Various treatment interventions have been used to give spasticity in children with CP. The choice to use any specific treatment intervention is conducted by the aim of the treatment. In some cases, the aim may be to decrease focal spasticity, while in others it may be to decrease generalized spasticity. Similarly, the risks and benefits of any particular intervention should be wisely considered. Physiotherapy and job-related therapy by age 4-5 years of age have been shown to be relatively more effective than if started at a future age. Botulinum toxin injection is used to treat focal spasticity with the best usefulness between 1 and 6 years of age for the treatment of lower extremity spasticity and between 5 and 15 years of age for spastic hemiplegia. Spasticity supervision is best conducted by a physician with expertise and experience with the use of various treatment interventions [9].

The GMFM has been applied widely. It has been adopted globally and has been used as a descriptive stratification system to discover a wide range of issues, such as the risk of hip migration in children with $\mathrm{CP}$ and the distribution of function in a population-based list of children and youths with CP [10]. These uses demonstrate how a consistent and valid functional classification system can be used to stratify children along with a specific attribute of the function. It can assist to classify the extent to which variations in that attribute contribute to variation in any of some other attributes.

Gross Motor Function Measure (GMFM) is a type of clinical measurement to evaluate changes in gross motor function of patients with CP. The measurement consists of 88 examination items; such as activities in the lying and rolling position (17 items), sitting (20 items), running, and jumping (12 items). The assessment of GMFM consists of 4 scores, each of which has the same meaning even though the description is different depending on the item's ability being assessed. The value of GMFM describes that $0=$ no initiative; 1 = there is an initiative; 2 = partially equipped; 3 = equipped; NT $=$ Not Tested (not tested).

\section{Method}

The application design in this study was developed using the Unified Software Development Process method and Unified Modeling Language (UML). UML was meant to be a unifying language enabling IT professionals to model computer applications. The Unified Software Development Process (USDP) or Unified Process (UP) is a methodology software development, especially oriented software object which consists of 4 phases; Inception, Elaboration, Construction, and Transition. The USDP method is more often used for a build framework (framework) that can be customized for the benefit of the organization and more specific projects [11].

The phases in the Unified Software Development Process or Unified Process based on Pressman [12]) consists of preliminary, expansion, design, and transition. This research includes the process of making a Software Requirements Specification and Software Design, then followed by making an application and closing with testing. This process is carried out continuously according to the planning period.

This research method includes interviews with physiotherapists at YPAC (Yayasan Pembinaan Anak Cacat - Disabled Children Development Foundation) in Surakarta which is a case study conducted for GMFM (Gross Motor Function Measure) with Cerebral Palsy cases. This method discusses the quality of the coordination patterns of motoric sensor problems and functionalities of daily life. The output of this phase is the specification of software requirements and interfaces. The output includes the initial interface design on the GMFM menu and the calculation of the GMFM dimension. The initial interface is then being analyzed to be a reference in developing a software requirements specification document.

Research [13] stated that the supervision contains neurological rehabilitation (addressing muscle tonal abnormalities, and devising bodily and work-related therapies) and identification and management of comorbidities (including epilepsy, impairment of cognition, visualization, hearing, and instabilities of growth and gastrointestinal utility). The supervision, consequently, is multidisciplinary including the treating physician working with a team of rehabilitation-, orthopedic, psychological-, and social care- providers. Moreover, research [14] specified that the effectiveness of rehabilitation interventions for children with CP is still questionable. Functional ability and social contribution should be the leading outcome measures in evaluating rehabilitation effectiveness. 


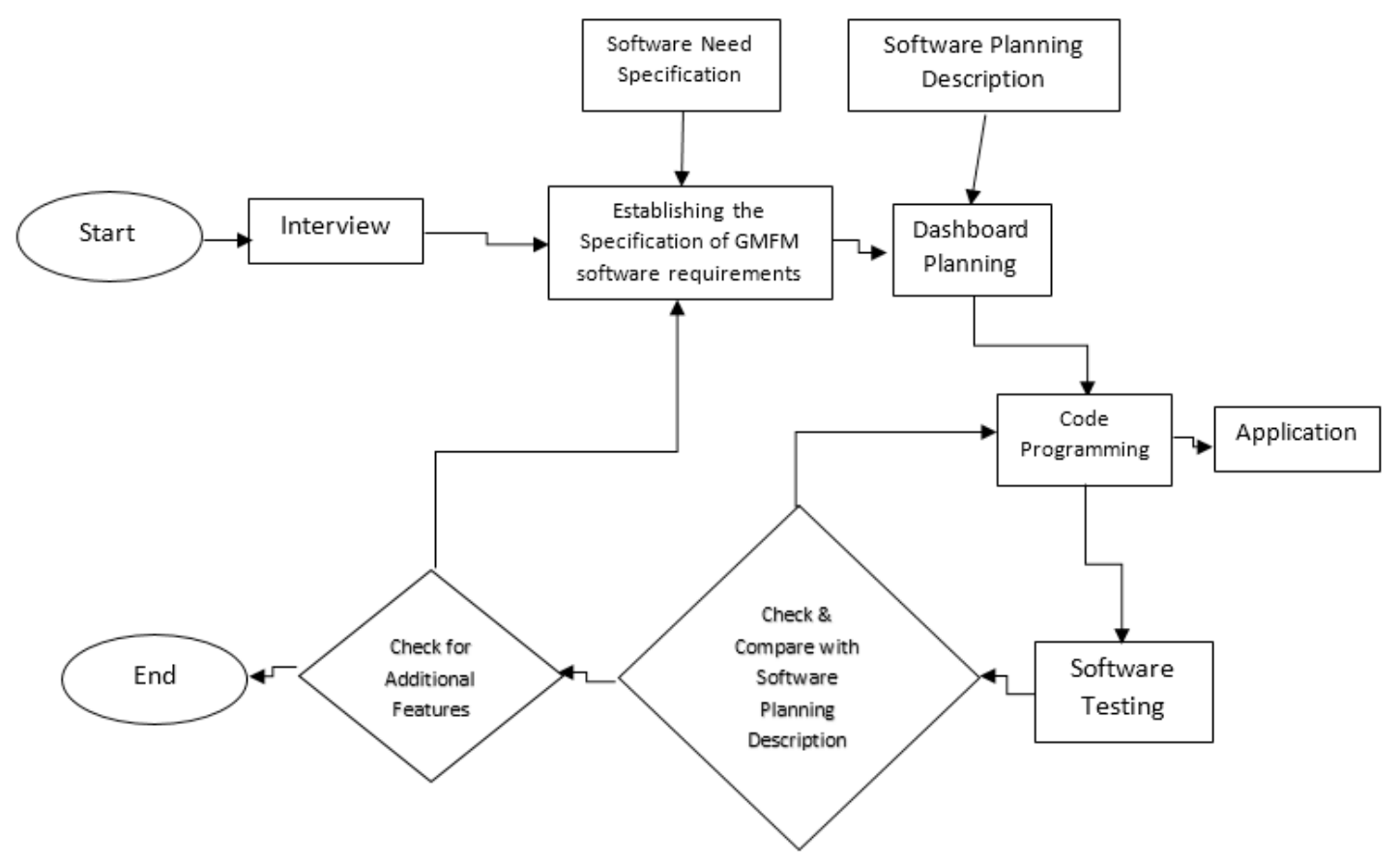

Research Flowchart

The diagnosis of spasticity in children with $\mathrm{CP}$ involves a comprehensive physical inspection, with additional testing as required [15]. The purpose of treatment is to encourage the child to acquire to be as independent as possible. Some children who have slight cerebral palsy will not take any difficulties in accomplishing independence. For others, it will be a slow process. In some with severe difficulties, considerable support from others will always be required. Specific treatment differs by individual and changes as needed if new issues develop. In general, treatment focuses on ways to maintain or improve a person's excellence of life and overall health.

The main interface displays the identity of the user, the identity of the $\mathrm{CP}$ patient, and the result of the measurement calculation of GMFM.

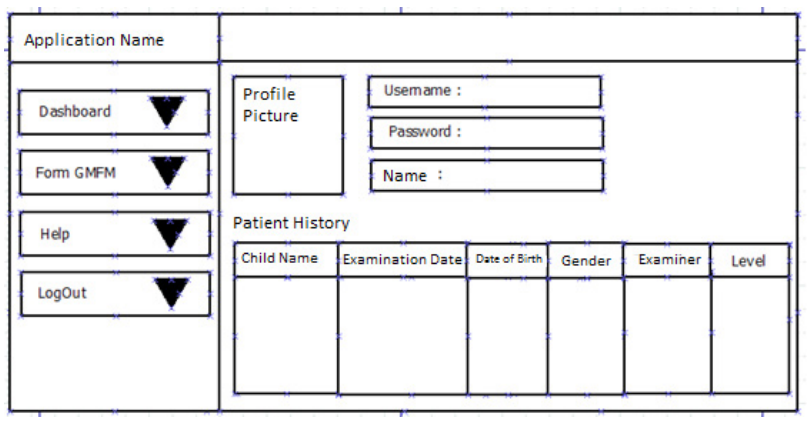

Main Interface Display Design

The design of the interface allows users to input some variable inputs; the name of the patient, birth date, gender, and GMFM level. There are two action buttons on the page, submit and reset. The submit button performs the input action that has been recorded while the reset button will cancel all entries. The interface is shown in figure 3 .

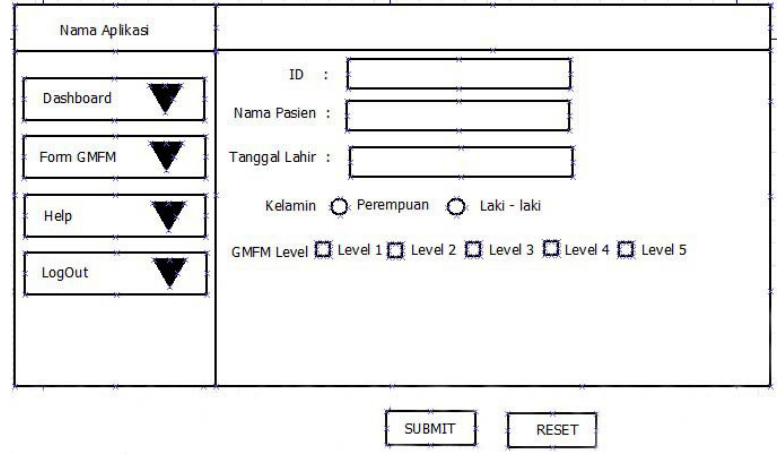

Entry data of the patient

The result of measurement is displayed in the other interface. The output will be recorded in percentage and graph. The application allows users to save the document in PDF format. The design of the output interface is shown in figure 4.

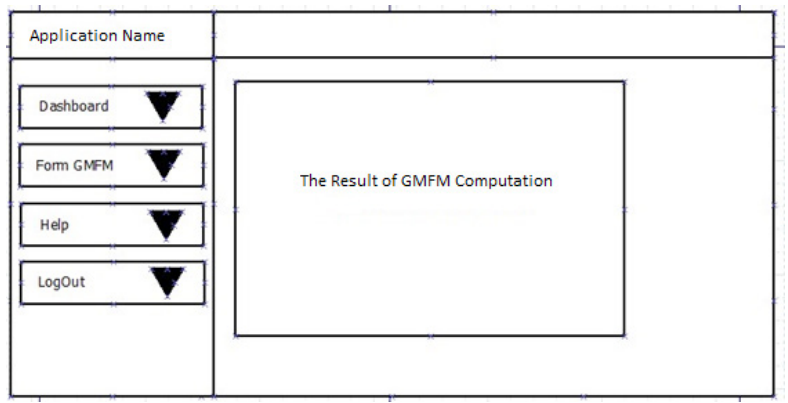

The Design interface of GMFM Measurement

The result of this stage is the specification of the software requirements document and the initial interface of the planning stage and then it is analyzed as a reference 
for making UML; such as use case, interface, database design, and system design. This application is developed by translating UML at the design stage into programming code.

Use case diagrams consist of actors as users that can be used in general. Actions that users allowed to take include inputting data, processing data, viewing data, and downloading data as shown in figure 5 .
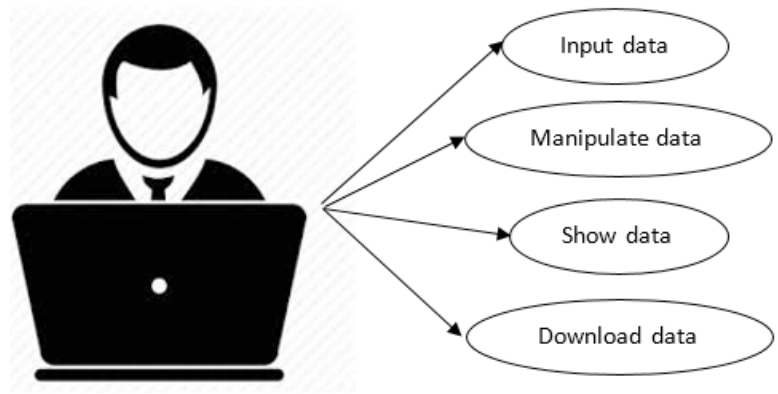

Use case diagram

Data taken include changes in functional capacity and GMFM (Gross Motor Function Measure). Functional capacity is measured from 0 (cannot be moved at all) to 1 (can do independently). GMFM (Gross Motor Function Measure) is a type of clinical measurement to evaluate changes in gross motor function of patients with CP. There are 88 examinations in GMFM.

a) GMFM dimension A (lying down): 17 examinations

b) GMFM dimension B (sitting): 20 examinations

c) GMFM dimension C (crawling): 14 examinations

d) GMFM dimension D (standing): 13 examinations

e) GMFM dimension E (running): 24 examinations

GMFM assessment consists of 4 scores; $0=$ no initiative, $1=$ there is an initiative, 2 = partially complete; 3 = complete; and NT= Not Tested. Therefore the maximum score are:

a) GMFM dimension A (lying down): 51

b) GMFM dimension B (sitting): 60

c) GMFM dimension C (crawling): 42

d) GMFM dimension D (standing): 39

e) GMFM dimension $\mathrm{E}$ (running): 72

The score of each dimension is converted into a percentage to calculate the GMFM score. The way to measure GMFM is if the dimension item is executed then $\mathrm{NT}=1$, and if the dimension item is not executed then $\mathrm{NT}=0$.

\section{Result and Discussion}

The application of motoric measurement of cerebral palsy children with GMFM consists of the initial appearance, dashboard, GMFM form, and also help menu that contains the terms and conditions. The initial page can be seen in Figure 6 . The initial page consists of a username, password, and name. There is a patient history table that shows a patient history that includes the child's name, date of examination, date of birth, sex, examiner, level, and the number of patients.

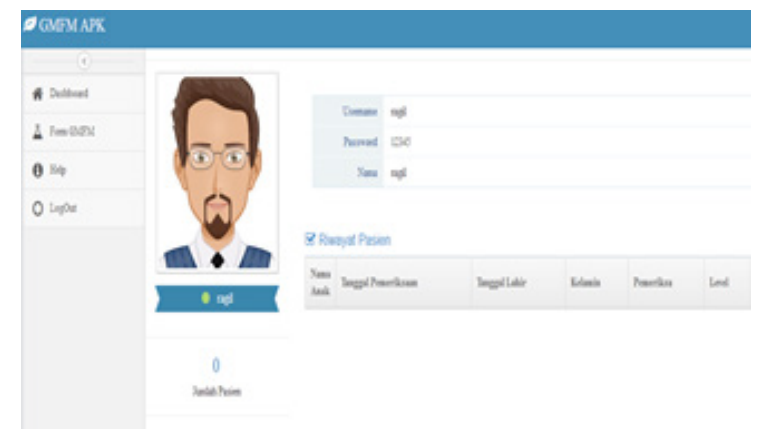

Figure 1. The initial page consists of the identity of the CP patient

The patient form page must be filled by the patient's identity then recorded to the system by the user which includes the id, the patient's name, date of birth, gender, and GMFM level. After the patient form is filled in, there are two button options; to record with submit button and to erase entry data or to repeat if there is an error in filling out the patient form with a reset button, as can be shown in Figure 7 .

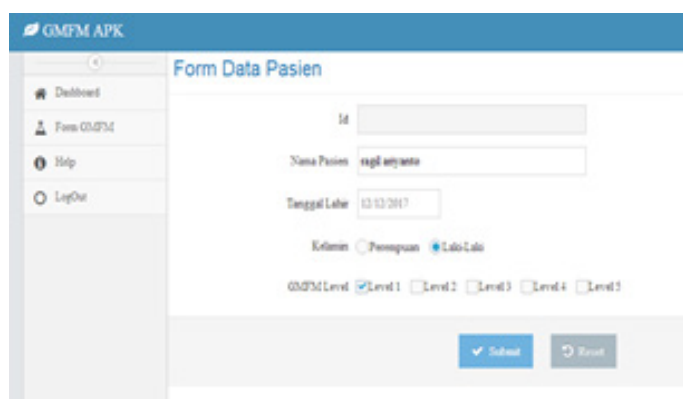

Figure 2. Patient Data Form

Figure 8 shows the content of a form that will be filled by the user and there are five dimensions of GMFM consisting of lying and rolling dimensions (17 items), sitting dimensions (20 items), crawling and kneeling dimensions (14 items), standing dimensions (13 items) and dimensions of walking, running, jumping. The way to assess there is no initiative (value 0 ) not test, there is an initiative (value 1), partially completed (value 2), completed (value 3 ) to choose according to the condition of patients to be tested. The results of selecting the GMFM dimension can be seen in Figure 8 .

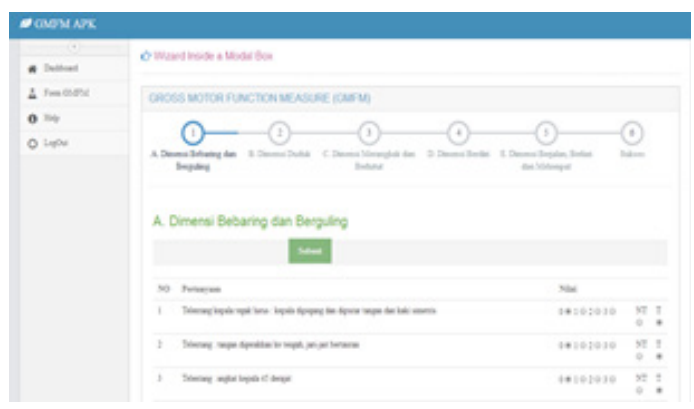

Figure 3. GMFM Item Measurement 
Figure 9 is the result of data entered by the user in the selection of dimension items. The user allows printing the result in PDF format. Data that has been recorded is then processed into information needed by the patient to perform motoric development.

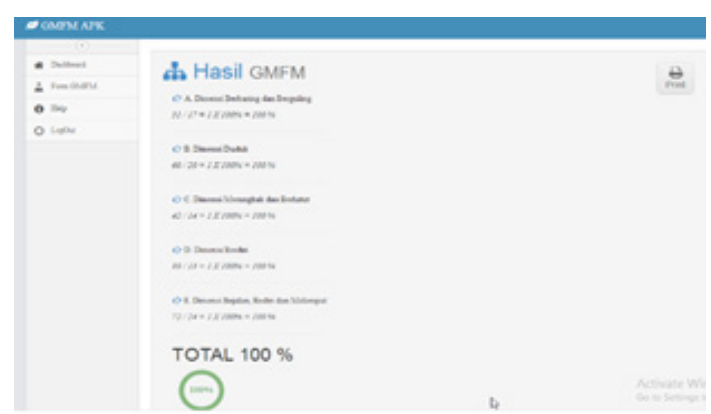

Figure 4. GMFM Measurement Result

The research conducts a black box testing method to evaluate the system. Software testing is necessary to ensure the applications that have been developed can run by the expected functionality[16]. Application testing is focused on the function of the motoric measurements, therefore the results show the accuracy of motoric measurements of the patient. Testing the motoric measurement application with the black box method can improve the quality of the system.

The formula used to calculate the measurement of a motoric parameter of the cerebral palsy patient.

$$
\begin{aligned}
X_{1}=\sum_{i=1}^{17} \frac{A_{i}}{51} ; X_{2} & =\sum_{i=1}^{20} \frac{B_{i}}{60} ; X_{3}=\sum_{i=1}^{14} \frac{C_{i}}{42} ; X_{4} \\
& =\sum_{i=1}^{13} \frac{D_{i}}{39} ; X_{5}=\sum_{i=1}^{24} \frac{E_{i}}{72}
\end{aligned}
$$

where $\mathrm{X}_{1}$ is the variable of the average score of dimension $\mathrm{A}$ (17 measurements of lie down and roll), $X_{2}$ is the variable of the average score of dimension B (20 measurements of sitting), $\mathrm{X}_{3}$ is the variable of the average score of dimension $\mathrm{C}$ (14 measurements of crawling and kneeling), $\mathrm{X}_{4}$ is the variable of the average score of dimension D (13 measurements of standing up) and $\mathrm{X}_{5}$ is the variable of the average score of dimension E (24 measurements of wall-run-jump). The total GMFM score is determined by the sum of all averages of the GMFM dimensional score.

Total Score of $G M F M=\sum_{i=1}^{\mathbf{5}} X_{i}$

The main definition of muscle strength is the value of the maximum ability of muscles or muscle groups to perform or maintain a certain pattern of movement[17]. The application of cerebral palsy motoric measurement provides significant improvements in gross motor function including a decrease in spasticity after the intervention within 6 weeks of treatment.
Measurement of functional ability with GMFM includes 88 items. This functional ability measurement is completed on lying and rolling, sitting, crawling and kneeling, standing items, and walking-running-jumping items. From the initial examination of T-1 until the final examination of T-6, the result shows the enhancement dimensions of lying and rolling by $13.3 \%$, sitting $14.8 \%$, crawling and kneeling by $15.7 \%$, standing by $16.5 \%$, and walking-running-jumping $17.4 \%$. Therefore, it can be concluded that the examination of functional abilities increased in every dimension of GMFM.

Table 1. The result of examination cerebral palsy patient

\begin{tabular}{clcccccc}
\hline No & Dimension & T1 & T2 & T3 & T4 & T5 & T6 \\
\hline 1 & $\begin{array}{l}\text { Lie down } \\
\text { and roll }\end{array}$ & $10,48 \%$ & $10,83 \%$ & $12,44 \%$ & $10,98 \%$ & $12,55 \%$ & $12,44 \%$ \\
& & & & & & \\
2 & Sitting & $13,25 \%$ & $13,44 \%$ & 14,48 & $16,55 \%$ & $17,83 \%$ & $17,83 \%$ \\
3 & Crawling & $14,44 \%$ & $15,83 \%$ & $16,55 \%$ & $17,55 \%$ & $17,25 \%$ & $17,83 \%$ \\
& $\begin{array}{l}\text { and } \\
\text { kneeling }\end{array}$ & & & & & & \\
4 & $\begin{array}{l}\text { Standing up } \\
5\end{array}$ & $12,55 \%$ & $17,83 \%$ & $18,48 \%$ & $18,83 \%$ & $19,48 \%$ & $19,98 \%$ \\
& $\begin{array}{l}\text { Walk, run } \\
\text { and jump }\end{array}$ & $15,44 \%$ & $16,48 \%$ & $16,98 \%$ & $18,83 \%$ & $17,48 \%$ & $18,98 \%$ \\
& Score & $13,3 \%$ & $14,8 \%$ & $15,7 \%$ & $16,5 \%$ & $16,9 \%$ & $17,4 \%$ \\
\hline
\end{tabular}

\section{Conclusion}

The application of a motoric cerebral palsy measurement is accomplished and meets with both the initial goal of application development and calculation analysis of motoric cerebral palsy. The data was recorded and being medical physiotherapy records. Data entry from the user processed and becomes historical medical record information for the cerebral palsy patient.

\section{Reference}

[1] H. D. of Republik Indonesia, "Profil Data Kesehatan Indonesia," 2011. http://www. depkes.go.id/downloads/profil_data_kesehatan_ indonesia_tahun_2011.pdf. (Accesed August 11th, 2017).

[2] C. Y. Pamilih, "Penatalaksanaan Neuro Development Treatment (NDT) Pada Kasus Cerebral Palsy Spastic Quadriplegi Di Yayasan Sayap Ibu Cabang Yogyakarta," Doctoral dissertation, Universitas Muhammadiyah Surakarta, 2014.

[3] D. Reddihough, "Cerebral Palsy in Childhood," Australian Family Physician, vol. 40, no. 4, April 2011.

[4] P. R. Yakkum, "Intervensi Medis dan Edukasi Keluarga Anak dengan Cerebral Palsy di Purworejo," 2015. http://library.ukdw.ac.id/ lppm\%20/index.php/sendimas2016/article/ view/54 (accessed April 6th, 2017)

[5] P. Aryani, "Case Report: Poor Nutrition on the Patient's Cerebral Palsy," Review of Primary Care 
Practice and Education, vol. 2, No. 1, 2019.

[6] Velde, A. Te, "Early Diagnosis and Classification of Cerebral Palsy: An Historical Perspective and Barriers to an Early Diagnosis," Journal of Clinical Medicine, vol. 8, 2019.

[7] M. S. J. Mohammad, "Cerebral Palsy: Comprehensive Review and Update," Annals of Saudi Medicine, 2006.

[8] M. D. Tommaso \& A. L. Tranquilli, "A checklist to identify the origin of cerebral palsy," The Journal of Maternal-Fetal \& Neonatal Medicine, vol. 15, no. 5, pp. 281-286, 2004, doi: 10.1080/14767050410001712121.

[9] D. R. Patel, "Cerebral Palsy in Children: a Clinical Overview," Translational Pediatrics, vol. 9, no. 1, pp. S125-S135, 2020 Feb.

[10] P. Rossenbaum, "Development of the Gross Motor Function Classification System for cerebral palsy," Developmental Medicine \& Child Neurology, vol. 50, pp. 249-253, 2008.

[11] Kurniada, D., "Perancangan Arsitektur Sistem E-academic dengan Konsep Kampus Digital Menggunakan Unified Software Development Process (USDP) Studi Kasus: AMIK Garut" Jurnal Wawasan Ilmiah Manajemen dan Teknik Informatika, Volume 5, No. 10, March 2014

[12] Pressman, R.S., "Rekayasa Perangkat Lunak Pendekatan Praktisi”. Andi Offset, Yogyakarta, 2012.

[13] S. Gulati, "Cerebral Palsy: An Overview," The Indian Journal of Pediatrics, vol. 85, pp. 10061016, 2017.

[14] A. Abbaskhanian, "Rehabilitation Interventions for Children with Cerebral Palsy: A Systematic Review,” Journal of Pediatrics Review (JPR), vol. 3, no. 1, 2015.

[15] S. Padmakar, "Management and Treatment for Cerebral Palsy in Children," Indian Journal of Pharmacy Practice, vol. 11, no. 2, Apr-Jun 2018.

[16] M. S. Mustaqbal, R. F. Firdaus, \& H. Rahmadi, "Pengujian Aplikasi Menggunakan Black Box Testing Bounday Value Analysis," Jurnal Ilmiah Teknologi Informasi Terapan, vol. 1, 2015

[17] J. Stoppani, "Encyclopedia of Muscle \& Strength," 2nd edition USA: Sheridan Books. 2006. 